\section{LEUCINOSTATINS H AND K, TWO NOVEL PEPTIDE ANTIBIOTICS WITH TERTIARY AMINE-OXIDE TERMINAL GROUP FROM PAECILOMYCES MARQUANDII ISOLATION, STRUCTURE AND BIOLOGICAL ACTIVITY}

Sir:

In a recent communication ${ }^{1)}$ we reported the isolation and structure elucidation of leucinostatin $\mathrm{D}$, a minor, biologically active, peptide component of the antibiotic mixture produced by submerged cultures of Paecilomyces marquandii (Massee) Hughes. In a search for further biologically active metabolites, the darkbrownish oily residue from the benzene extract of the culture broth was subjected to repeated fiash chromatography on silica gel colums using $\mathrm{CHCl}_{3}$ as the eluent to which $\mathrm{MeOH}$ and $\mathrm{NH}_{3}$ were added in continuously increasing proportions up to final composition $\mathrm{CHCl}_{3}-\mathrm{MeOH}$ $\mathrm{NH}_{3}, 80: 18: 2$. At the end of this procedure, a fractions was obtained that consisted mainly of two new peptidic components we have labeled leucinostatins $\mathrm{H}$ and $\mathrm{K}$. These were separated and purified through repeated flash chromatography under $\mathrm{N}_{2}$ atmosphere using final solvent mixture $\mathrm{CHCl}_{3}-\mathrm{MeOH}-\mathrm{NH}_{3}$ as the eluent. Evaporation of the solvents gave leucinostatin $H(\mathbf{1}$, Rf 0.4$)$ as a white, partly crystalline material ( $\mathrm{mp} 166 \sim 168^{\circ} \mathrm{C}$ ) and leucinostatin $\mathrm{K}$ $(2, \mathrm{Rf} 0.45)$ as white amorphous solid $(\mathrm{mp} 138 \sim$ $141^{\circ} \mathrm{C}$ ). (Rf values refer to the final solvent mixture.)

While the fourier transform (FT) IR and UV/ vis spectra of the new metabolites provided values very similar to those obtained for other leucinostatin components described earlier ${ }^{1 \sim 3}$, fast atom bombardment (FAB) mass spectra, remarkably displaying the $\mathrm{M}+\mathrm{H}$ ions only, suggested that peptides $\mathbf{1}[\mathrm{m} / \mathrm{z}$ (nominal mass) $1,134]$ and $2(\mathrm{~m} / \mathrm{z} 1,234)$ might correspond to leucinostatins $\mathrm{D}(3, \mathrm{~m} / \mathrm{z} 1,118)^{1)}$ and $\mathrm{A}(4, m / z$ $1,218)^{2,3)}$ with an additional oxygen atom in the molecules.

Supporting evidence for this structural relationship and information as to the site of oxidation were conveniently inferred from the highfield NMR spectra. Detailed analysis of the conventional (1D) and two-dimensional (2D) ${ }^{13} \mathrm{C}(100 \mathrm{MHz})$ and ${ }^{1} \mathrm{H}(400 \mathrm{MHz})$ spectra disclosed that $\mathbf{1}$ and $\mathbf{3}$ and, in a similar manner, 2 and 4 consist, pairwise, of the same amino acid residues arranged in identical sequences. Multiplicity-selected carbon- 13 spectra, on the other hand, revealed that incorporation of the extra oxygen atom into the metabolites entails no changes in the total number of carbon-bonded hydrogen atoms, a finding that suggests $\mathrm{N}$ oxidation. From the comparison of the fully assigned ${ }^{13} \mathrm{C}$ and ${ }^{1} \mathrm{H}$ chemical shift data of $\mathbf{1}$ and 2 with those of their assumed non-oxygenated counterparts, 3 and 4 , it became evident that the oxidation-induced changes in the chemical shifts are restricted to nuclei in the 1-(dimethylamino)2-aminopropane unit. More specifically, as attested by the chemical shift data in Table 1, we found that, e.g. from 3 to 1 , the chemical shift values of carbon atoms located in this part of the molecule undergo variations typical of oxygen substitution at the quaternary nitrogen atom. (Note the characteristic $\beta, \gamma$ and $\delta$ substituent effects at the pertinent carbon sites.) Less distinct, but equally characteristic, are the changes observed for the chemical shifts of protons in this moiety. Here, we found $\sim 0.3$ ppm downfield shift of resonances due to protons in $\beta$-position relative to the site of oxidation, again an effect best accounted for by considering oxygen substitution of the (protonated) quaternary nitrogen atom. A practically identical

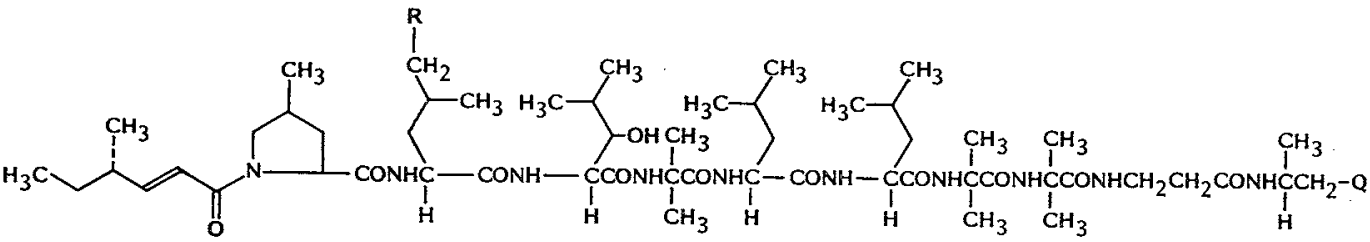

$$
\begin{aligned}
& 1 \quad \mathrm{R}=\mathrm{H} \\
& 2 \mathrm{R}=\mathrm{CH}(\mathrm{OH}) \mathrm{CH}_{2} \mathrm{COCH}_{2} \mathrm{CH}_{3} \quad \mathrm{Q}=\mathrm{NO}\left(\mathrm{CH}_{3}\right)_{2} \\
& 3 \mathrm{R}=\mathrm{H} \quad \mathrm{Q}=\mathrm{N}^{+} \mathrm{H}\left(\mathrm{CH}_{3}\right)_{2} \\
& 4 \mathrm{R}=\mathrm{CH}(\mathrm{OH}) \mathrm{CH}_{2} \mathrm{COCH}_{2} \mathrm{CH}_{3} \quad \mathrm{Q}=\mathrm{N}^{+} \mathrm{H}\left(\mathrm{CH}_{3}\right)_{2}
\end{aligned}
$$


Table $1 .{ }^{13} \mathrm{C}$ and ${ }^{1} \mathrm{H}$ Chemical shifts of the 1 (dimethylamino)-2-amino-propane unit in leucinostatins $\mathrm{D}(\mathbf{3})$ and $\mathrm{H}(\mathbf{1})^{*}$.

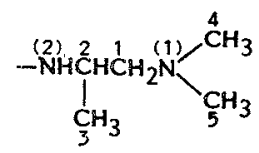

\begin{tabular}{lccc}
\hline & $\begin{array}{c}3 \\
\text { (free base) }\end{array}$ & $\begin{array}{c}3 \\
\text { (HCI salt) }\end{array}$ & $\mathbf{1}$ \\
\hline Carbon & & & \\
$\mathrm{C1}$ & 64.69 & 62.65 & 75.19 \\
$\mathrm{C} 2$ & 43.44 & 40.12 & 39.93 \\
$\mathrm{C} 3$ & 19.07 & 18.45 & 21.50 \\
$\mathrm{C} 4$ & 45.76 & 46.58 & 59.68 \\
$\mathrm{C} 5$ & 45.76 & 42.50 & 54.69 \\
Proton & & & \\
$1-\mathrm{H}_{\mathrm{A}}$ & 2.22 & 3.01 & 3.21 \\
$1-\mathrm{H}_{\mathrm{B}}$ & 2.35 & 3.81 & 4.13 \\
$2-\mathrm{H}$ & 4.02 & 4.63 & 4.80 \\
$3-\mathrm{H}_{3}$ & 1.18 & 1.28 & 1.31 \\
$4-\mathrm{H}_{3}$ & 2.22 & 3.04 & 3.34 \\
$5-\mathrm{H}_{3}$ & 2.22 & 3.13 & 3.38 \\
$\mathrm{~N}(1)^{+}-\mathrm{H}$ & - & 8.13 & - \\
$\mathrm{N}(2)-\mathrm{H}$ & 6.83 & 7.26 & 7.61 \\
\hline
\end{tabular}

* Chemical shifts $\left(\mathrm{CDCl}_{3}\right)$ are in ppm relative to internal TMS.

Table 2. Antibacterial and antimycotic activity of leucinostatins $\mathrm{H}(\mathbf{1})$ and $\mathrm{K}(2)^{*}(\mathrm{MIC}, \mu \mathrm{g} / \mathrm{ml})$.

\begin{tabular}{lrr}
\hline \multicolumn{1}{c}{ Microorganism } & \multicolumn{1}{c}{$\mathbf{1}$} & \multicolumn{1}{c}{$\mathbf{2}$} \\
\hline Bacillus subtilis ICI & 100 & 100 \\
B. subtilis var. niger & 25 & 25 \\
B. cereus B43 1335 & 100 & 50 \\
Micrococcus luteus ISS & 25 & 25 \\
Staphylococcus aureus & 10 & 25 \\
Pseudomonas aeruginosa 6750 & $>100$ & $>100$ \\
Salmonella typhimurium & $>100$ & $>100$ \\
Proteus vulgaris & $>100$ & $>100$ \\
Escherichia coli 982 & $>100$ & $>100$ \\
Citrobacter freundii & $>100$ & $>100$ \\
Pseudomonas fluorescens & $>100$ & $>100$ \\
Candida albicans CBS 562 & 10 & 25 \\
C. tropicalis 5711 IMAT & 25 & 50 \\
C. guilliermondii 5319 & 25 & $>10$ \\
C. krusei CBS 1910 & 10 & $<2$ \\
Cryptococcus laurentii 4685 & 10 & 10 \\
C. neoformans 4711 IMAT & 2 & 2 \\
\hline
\end{tabular}

* MIC values were determined after 48 hours of incubation. Media for bacteria consisted of nutritive agar broth, for fungi SABOURAUD's dextrose broth. set of chemical shift data was found for the pair 2 and 4. Corroborative chemical evidence for the correctness of structures $\mathbf{1}$ and $\mathbf{2}$ was readily available by $\mathrm{N}$-oxidation of $\mathbf{3}$ via $\mathrm{m}$-Cl-perbenzoic acid treatment (in dry $\mathrm{CH}_{2} \mathrm{Cl}_{2}$ at room temperature). The resulting product proved, in every respect, identical with 1 .

It may be noted that structures $\mathbf{1}$ and $\mathbf{2}$ also provide an immediate rationale for the aforementioned lack of fragmentation ions in the FAB mass spectra of the new metabolites. In contrast to the non-oxygenated leucinostatins, where formation of the $\mathrm{M}+\mathrm{H}$ ions is greatly facilitated by the availability of quaternary $\mathrm{N}$ atoms, $\mathrm{N}$-oxidation, as in $\mathbf{1}$ and $\mathbf{2}$, clearly renders this process highly unfavored. This results in a major drop in the ion currents making the fragmentation pattern undetectable under normal experimental conditions.

Leucinostatins $\mathrm{H}$ and $\mathrm{K}$ show biological activity against Gram-positive bacteria and fungi as do the respective leucinostatins $\mathbf{D}$ and $\mathrm{A}^{1,2}$. However, as demonstrated by the MIC values in Table 2, both the antibacterial and the antimycotic activities become significantly reduced upon $\mathrm{N}$-oxidation. In a similar manner, $\mathrm{N}$ oxidation causes a nearly 2 -fold decrease in the phytotoxic activity ${ }^{4}$; irreversible withering of tomato cuttings became visible after 72 hours at 10 and $5 \mu \mathrm{g} / \mathrm{ml}$ concentrations of 1 and 2 , respectively.

$\mathrm{N}$-Oxides are known to occur frequently in nature ${ }^{53}$ and it is generally believed that their presence is connected with processes leading to $N$-dealkylation of natural products ${ }^{(\sim 9)}$. While the exact biogenetic role of $\mathbf{1}$ and $\mathbf{2}$ may require further clarification, we mention here that sizable amounts of nor-3) and bisnor-leucinostatin $\mathrm{A}^{10)}$ have, in fact, been detected by us in the culture filtrates of $P$. marquandii.

In a recent communication describing the identification of leucinostatin components from Paecilomyces lilacinus A-257 by means of directly coupled liquid chromatography/FAB mass spectrometry, STROH et al. ${ }^{11}$ have reported the detection of two minor components in such a low abundance that only molecular weight information could be obtained. The reported mass values, however, suggest that the two new components may prove to be identical with leucinostatins $\mathrm{H}$ and $\mathrm{K}$. 


\section{Acknowledgments}

This work has been supported, in part, by the grant of the Italian National Research Council (C.N.R.) "Progetto-finalizzato, Chimica Fine e Secondaria."

\section{LAJOS RADICS \\ MARIa KaJTAR-PEREDY}

Central Research Institute of Chemistry, P.O. Box 17, H-1525 Budapest, Hungary

\section{Carlo G. Casinovi}

Laboratorio Chimica del Farmaco, Istituto Superiore di Sanità, I-00161 Rome, Italy

\section{Carlo Rossi \\ Maurizio RicCi \\ LORENZO TUTTOBELLO}

Istituto Chimica Farmaceutica,

Università degli Studi di Perugia, I-06100 Perugia, Italy

(Received November 7, 1986)

\section{References}

1) Rossi, C.; L. Tuttobello, M. Ricci, C. G. Casinovr \& L. Radics: Leucinostatin D, a novel peptide antibiotic from Paecilomyces marquandii. J. Antibiotics 40: $130 \sim 133,1987$

2) Casinovi, C. G.; L. Tuttobello, C. Rossi \& Z. BENCIARI: Structural elucidation of the phytotoxic antibiotic peptides produced by submerged cultures of Paecilomyces marquandii (Massee) Hughes. Phytopathol. Mediterr. 22: $103 \sim 106,1983$
3) Rossi, C.; Z. Benciari, C. G. Casinovi \& L. Tuttonello: Two phytotoxic antibiotic peptides produced by submerged cultures of Paecilomyces marquandii (Massee) Hughes. Phytopathol. Mediterr, 22: 209 211, 1983

4) Ballio, A.; A. Carilli, B. Santurbano \& L. TutToBello: Production of fusicoccsine on pilot-plant scale. Ann. Ist. Super. Sanità 4: $317 \sim 326,1968$

5) Phillipson, J. D. \& S.S. Handa: Alkaloid $\mathrm{N}$-oxides. A review of recent developments. Lloydia 41: 385 431, 1978

6) Craig, J. C.; F. P. Dwyer, A. N. Glazer \& E. C. Horning: Tertiary amine oxide rearrangements I. Mechanism. J. Am. Chem. Soc. 83: $1871 \sim 1878,1961$

7) Gosal, S. \& B. MukKherjee: Indole-3-alkylamine bases of Desmodium pulchellum. J. Org. Chem. 31 : 2284 2288, 1966

8) Ferris, J. P.; R.D. Gerwb \& J. R. GAPSKI: Detoxification mechanism III. The scope and mechanism of the non-catalyzed dealkylation of tertiary amine-oxides. J. Org. Chem. 33: $3493 \sim 3498,1968$

9) Scherer, C. A.; C. A. Darschel, J. M. CoOK \& P. W. Lequesne: A model for iron-catalyzed biomimetic cyclization of a tryptamine $N$-oxide. J. Org. Chem. 37: 1083 1085, 1978

10) Casinovi, C. G.; C. Rossi, L. Tuttobello \& M. RICCr: The structure of leucinostatin C, a minor peptide from Paecilomyces marquandii. Eur. J. Med. Chem. 21: 527 528, 1986

11) Stroh, J. G.; K. L. Rinehart, Jr., J. C. Cook, T. Kihara, M. SuzUKI \& T. AraI: Identification and structure assignment of components of leucinostatin and $\mathrm{CC}-1014$ by directly coupled liquid chromatography/fast atom bombardment mass spectrometry. J. Am. Chem. Soc. 108: $858 \sim 859,1986$ 